\title{
A Sequential Fluid- Mechanic Chemical-Kinetic Model of Propane HCCI Combustion
}

S. M. Aceves, D. L. Flowers, J. Martinez-Frias, J. R. Smith, C. K. Westbrook. W. J. Pitz, R. Dibble, J. F. Wright, W. C. Akinyemi, R. P. Hessel

This article was submitted to Society of Automotive Engineers 2001 World Congress, Detroit, Michigan, March 5-8, 2001

U.S. Department of Energy

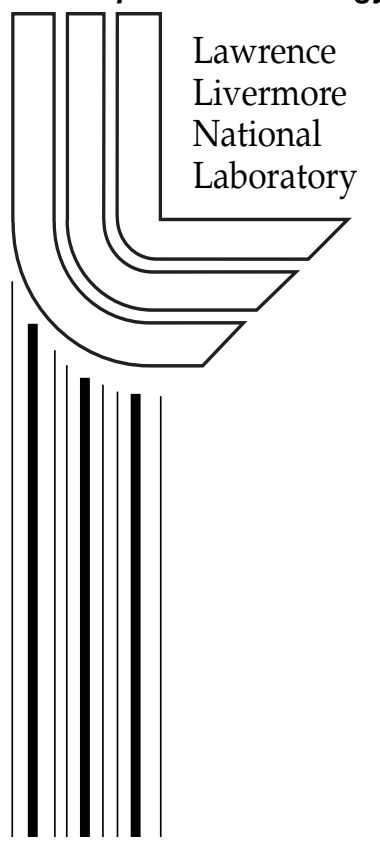

November 29, 2000 


\section{DISCLAIMER}

This document was prepared as an account of work sponsored by an agency of the United States Government. Neither the United States Government nor the University of California nor any of their employees, makes any warranty, express or implied, or assumes any legal liability or responsibility for the accuracy, completeness, or usefulness of any information, apparatus, product, or process disclosed, or represents that its use would not infringe privately owned rights. Reference herein to any specific commercial product, process, or service by trade name, trademark, manufacturer, or otherwise, does not necessarily constitute or imply its endorsement, recommendation, or favoring by the United States Government or the University of California. The views and opinions of authors expressed herein do not necessarily state or reflect those of the United States Government or the University of California, and shall not be used for advertising or product endorsement purposes.

This is a preprint of a paper intended for publication in a journal or proceedings. Since changes may be made before publication, this preprint is made available with the understanding that it will not be cited or reproduced without the permission of the author.

This work was performed under the auspices of the United States Department of Energy by the University of California, Lawrence Livermore National Laboratory under contract No. W-7405-Eng-48.

This report has been reproduced directly from the best available copy.

Available electronically at http://www.doc.gov/bridge

Available for a processing fee to U.S. Department of Energy

And its contractors in paper from

U.S. Department of Energy

Office of Scientific and Technical Information

P.O. Box 62

Oak Ridge, TN 37831-0062

Telephone: (865) 576-8401

Facsimile: (865) 576-5728

E-mail: reports@adonis.osti.gov

Available for the sale to the public from

U.S. Department of Commerce

National Technical Information Service

5285 Port Royal Road

Springfield, VA 22161

Telephone: (800) 553-6847

Facsimile: (703) 605-6900

E-mail: orders@ntis.fedworld.gov

Online ordering: http://www.ntis.gov/ordering.htm

OR

Lawrence Livermore National Laboratory

Technical Information Department's Digital Library

http://www.llnl.gov/tid/Library.html 


\section{DISCLAIMER}

This document was prepared as an account of work sponsored by an agency of the United States Government. Neither the United States Government nor the University of California nor any of their employees, makes any warranty, express or implied, or assumes any legal liability or responsibility for the accuracy, completeness, or usefulness of any information, apparatus, product, or process disclosed, or represents that its use would not infringe privately owned rights. Reference herein to any specific commercial product, process, or service by trade name, trademark, manufacturer, or otherwise, does not necessarily constitute or imply its endorsement, recommendation, or favoring by the United States Government or the University of California. The views and opinions of authors expressed herein do not necessarily state or reflect those of the United States Government or the University of California, and shall not be used for advertising or product endorsement purposes.

This is a preprint of a paper intended for publication in a journal or proceedings. Since changes may be made before publication, this preprint is made available with the understanding that it will not be cited or reproduced without the permission of the author.

This work was performed under the auspices of the United States Department of Energy by the University of California, Lawrence Livermore National Laboratory under contract No. W-7405-Eng-48.

This report has been reproduced directly from the best available copy.

Available electronically at http://www.doc.gov/bridge

Available for a processing fee to U.S. Department of Energy

And its contractors in paper from

U.S. Department of Energy

Office of Scientific and Technical Information

P.O. Box 62

Oak Ridge, TN 37831-0062

Telephone: (865) 576-8401

Facsimile: (865) 576-5728

E-mail: reports@adonis.osti.gov

Available for the sale to the public from

U.S. Department of Commerce

National Technical Information Service

5285 Port Royal Road

Springfield, VA 22161

Telephone: (800) 553-6847

Facsimile: (703) 605-6900

E-mail: orders@ntis.fedworld.gov

Online ordering: http://www.ntis.gov/ordering.htm

OR

Lawrence Livermore National Laboratory

Technical Information Department's Digital Library

http://www.llnl.gov/tid/Library.html 


\title{
A Sequential Fluid-Mechanic Chemical-Kinetic Model of Propane HCCI Combustion
}

\author{
Salvador M. Aceves, Daniel L. Flowers, Joel Martinez-Frias, \\ J. Ray Smith, Charles Westbrook and William Pitz \\ Lawrence Livermore National Laboratory \\ Robert Dibble \\ University of California Berkeley \\ John F. Wright, Wole C. Akinyemi \\ Cummins Engine Company \\ Randy P. Hessel \\ University of Wisconsin-Madison
}

\begin{abstract}
We have developed a methodology for predicting combustion and emissions in a Homogeneous Charge Compression Ignition (HCCI) Engine. This methodology combines a detailed fluid mechanics code with a detailed chemical kinetics code. Instead of directly linking the two codes, which would require an extremely long computational time, the methodology consists of first running the fluid mechanics code to obtain temperature profiles as a function of time. These temperature profiles are then used as input to a multi-zone chemical kinetics code. The advantage of this procedure is that a small number of zones (10) is enough to obtain accurate results. This procedure achieves the benefits of linking the fluid mechanics and the chemical kinetics codes with a great reduction in the computational effort, to a level that can be handled with current computers. The success of this procedure is in large part a consequence of the fact that for much of the compression stroke the chemistry is inactive and thus has little influence on fluid mechanics and heat transfer. Then, when chemistry is active, combustion is rather sudden, leaving little time for interaction between chemistry and fluid mixing and heat transfer. This sequential methodology has been capable of explaining the main characteristics of HCCI combustion that have been observed in experiments.
\end{abstract}

In this paper, we use our model to explore an HCCI engine running on propane. The paper compares experimental and numerical pressure traces, heat release rates, and hydrocarbon and carbon monoxide emissions. The results show an excellent agreement, even in parameters that are difficult to predict, such as chemical heat release rates. Carbon monoxide emissions are reasonably well predicted, even though it is intrinsically difficult to make good predictions of $\mathrm{CO}$ emissions in $\mathrm{HCCI}$ engines. The paper includes a sensitivity study on the effect of the heat transfer correlation on the results of the analysis. Importantly, the paper also shows a numerical study on how parameters such as 
swirl rate, crevices and ceramic walls could help in reducing $\mathrm{HC}$ and $\mathrm{CO}$ emissions from HCCI engines.

\section{Introduction}

Homogeneous Charge Compression Ignition (HCCI) engines are being considered as a future alternative for diesel engines. HCCI engines have the potential for high efficiency (diesel-like [1]), very low nitrogen oxide $\left(\mathrm{NO}_{\mathrm{x}}\right)$ and particulate matter emissions, and low cost (because no high-pressure injection system is required). Disadvantages of HCCI engines are high hydrocarbon (HC) and carbon monoxide (CO) emissions, high peak pressures, high rates of heat release, reduced operating range, reduced power per displacement, and difficulty in starting and controlling the engine. Some of these disadvantages may be reduced or eliminated by operating the HCCI engine in hybrid mode, where the engine operates in HCCI mode at low power and in spark-ignited mode [2] or diesel mode [3] at high power. This hybrid mode takes advantage of the high efficiency and low $\mathrm{NO}_{\mathrm{x}}$ and particulate matter emissions of HCCI engines at low power conditions while reducing or eliminating the power limitations and startability problems of HCCI engines.

It is widely accepted that HCCI combustion is dominated by chemical kinetics [4], with no requirement for flame propagation. This notion has been supported by spectroscopy experiments, which indicate that the order of radical formation in $\mathrm{HCCI}$ combustion correspond to self-ignition instead of flame propagation [5,6]. If a truly homogeneous mixture exists at the time of combustion, turbulence has little direct effect on HCCI combustion, but it may have an indirect effect by altering the temperature distribution and the boundary layer thickness within the cylinder. Small temperature differences inside the cylinder have a considerable effect on combustion because chemical kinetics is very sensitive to temperature.

Turbulence introduces great complexity to the analysis of spark-ignited and compressionignited engines. The fact that HCCI combustion is not very sensitive to turbulence makes it possible to develop a thorough, accurate method of analysis of HCCI combustion. In principle, this comprehensive tool could be obtained by combining a fluid mechanics code with a detailed chemical kinetics code. In this approach, the fluid mechanics code would calculate the temperature distribution within the cylinder, and the chemical kinetics code would calculate chemical heat release as a function of pressure, temperature and composition. However, direct linking of a detailed fluid mechanics code with a detailed chemical kinetics code is well beyond our current computational capabilities. Considering that even a two-dimensional grid requires thousands of elements for obtaining a good definition of the boundary layer and crevices, solving this problem would imply having to solve for thousands of well-stirred reactors, interacting with one another through heat transfer, diffusion, convection, and compression work. This is an intractable task for current computers, even when the simplest fuels (e.g., hydrogen, methanol) are considered. 
Instead of attempting to directly link a fluid mechanics code with a chemical kinetics code, we have developed an alternative, sequential procedure for analysis of HCCI combustion [7]. The procedure uses a two-step approach. First, a fluid mechanics code (KIVA3V [8]) is used to calculate temperature histories during the compression stroke. The engine geometry-specific information calculated by KIVA3V in the form of the temperature histories is then handed off to a detailed chemical kinetics code (HCT; Hydrodynamics, Chemistry and Transport [9]). HCT operates in multi-zone mode, with geometry-independent zones. The advantage of this KIVA3V-HCT procedure is that a small number of HCT zones (10) is enough to obtain accurate results. This procedure achieves the benefits of linking the fluid mechanics and the chemical kinetics with a great reduction in the computational effort, to a level that can be handled with current computers. The methodology also shows promise for generating quantitative predictions for $\mathrm{HC}$ and $\mathrm{CO}$ emissions, and it is capable of predicting where in the cylinder the different pollutants are being generated. In addition to this, this method offers insight into the detailed chemical kinetics of the HCCI combustion process.

This KIVA3V-HCT sequential methodology has been capable of explaining the main characteristics of HCCI combustion that have been previously observed in experiments. High $\mathrm{HC}$ and $\mathrm{CO}$ emissions are shown to result from crevices and boundary layers, which are too cold for reaction completion. This has been verified by experiments in which the use of low crevice and hot wall engines has resulted in reduced $\mathrm{HC}$ emissions $[10,11]$. Maximum temperatures inside an HCCI engine are typically low enough that very little $\mathrm{NO}_{\mathrm{x}}$ is generated. Lean, homogeneous combustion results in negligible particulate matter emissions. Hot EGR enhances HCCI combustion mainly due to the higher temperature of the resulting intake mixture, and, based on our previous modeling, not due to the carry-over of "active radicals" in EGR.

In this paper, the sequential multi-zone model is applied to analyze an HCCI engine running on propane. The paper compares experimental and numerical pressure traces, heat release rates, and hydrocarbon and carbon monoxide emissions. The results show an excellent agreement, even in parameters that are difficult to predict, such as heat release rates. Carbon monoxide emissions are reasonably well predicted, even though it is intrinsically difficult to make good predictions of $\mathrm{CO}$ emissions in $\mathrm{HCCI}$ engines. The paper includes a sensitivity study on the effect of the heat transfer correlation on the results of the analysis. Importantly, the paper also shows numerical results on how parameters such as swirl rate, crevices and ceramic walls could help in reducing HC and $\mathrm{CO}$ emissions from $\mathrm{HCCI}$ engines.

\section{Analysis}

This section gives a brief description of the sequential multi-zone methodology for analysis of HCCI combustion. For further details, the reader is referred to our previous paper [7]. 
The procedure, as described here, applies to a well-mixed charge, although it could be modified to run for a non-homogeneous composition. Figure 1 illustrates the overall sequence of calculations. The procedure is started by making a KIVA3V run considering motored (no ignition) conditions. KIVA3V is used in its original form, with no modifications. The resulting temperature distribution, shown in Figure 1(a), is then converted into a temperature mass distribution. The temperature mass distribution gives the fraction of the total mass in the cylinder that has a certain temperature. Figure 1(b) shows a typical temperature mass distribution at $5^{\circ}$ BTDC and a cumulative mass distribution, which indicates the fraction of the mass that is colder than a specified temperature $\mathrm{T}$. The mass within the cylinder is then divided into zones. The number of zones is selected, as well as a mass distribution within the zones. Based on previous work, 10 zones have been selected, with the following mass distribution within the zones:

\begin{tabular}{|l|l|l|l|l|l|l|l|l|l|l|}
\hline $\begin{array}{l}\text { Zone } \\
(1=\text { coldest } \\
10=\text { hottest }\end{array}$ & 1 & 2 & 3 & 4 & 5 & 6 & 7 & 8 & 9 & 10 \\
\hline $\begin{array}{l}\text { mass in } \\
\text { zone, } \%\end{array}$ & 1 & 1 & 1 & 1 & 1 & 2 & 6 & 17 & 30 & 40 \\
\hline
\end{tabular}

Figure 1(b) also shows the distribution of zones in the temperature domain. Zone average temperatures and boundaries are indicated by dots and lines. The figure indicates that zones 1-5 occupy a wider range of temperature than zones 6-10, even though they include a much smaller fraction of the total mass.

The temperature mass distributions are then used for assigning a temperature history to the ten zones. From the temperature distributions, zone 1 receives the average temperature of the coldest $1 \%$ of the mass, zone 2 has the temperature of the next coldest $1 \%$, and so on until zone 10 , which has the average temperature of the hottest $40 \%$ of the mass. This calculation is repeated for multiple crank angles to determine the temperature history for the zones. Figure 1(c) shows a temperature history for each of the 10 zones. The temperatures calculated from KIVA3V are used only until ignition is achieved (see below). Figure 1(c) also shows that the temperature of some zones (1-4) drops during the compression stroke due to heat transfer to the wall.

The final step consists of making a detailed chemical kinetic analysis of the process with HCT in multi-zone mode to calculate all combustion parameters, including pressure, burn duration, heat release, efficiency, emissions, radical concentration (Figure 1(d)) and all the details about the chemical kinetics of HCCI combustion. The temperatures of the zones for the HCT run are specified by the temperature histories obtained from KIVA3V (Figure 1(c)). These temperature histories are the geometry-specific information that is handed from KIVA3V to HCT to link the two codes and yield results that fully consider the effect of both fluid mechanics and chemical kinetics.

An important issue with the HCT run is chemical heat release. It is clear that the temperature histories calculated from KIVA3V for a motored engine are not valid if 
substantial heat release occurs. For this reason, the KIVA3V temperature distribution is followed only until a certain amount of chemical heat release has taken place. At this moment, the KIVA3V temperature histories are abandoned, and instead temperatures determined from HCT with the Woschni heat transfer correlation [12] are used until the end of the run. Based on our previous experience, the KIVA3V temperature histories are used until $5 \%$ of the total available heat release has occurred. The transition between KIVA3V and HCT temperatures is illustrated in Figure 1(c) by a vertical line and a sudden change in slope in the temperature lines.

The Woschni heat transfer correlation is implemented in the model by assuming that heat transfer is divided evenly among zones $1-5$. These zones include the crevice and boundary layer, and are the zones directly in contact with the wall [7]. Zones 6-10, representing the central core, are assumed to be adiabatic.

The chemical kinetics code HCT has the capability to take into account diffusion and heat transfer between zones, and we have included these effects in much of our preliminary work. However, we have shown through sensitivity analysis that diffusion and heat transfer between zones have a very small effect on HCCI combustion. Therefore, our current model considers that the different zones interact very weakly with each other. The only interaction included is the compression work that a zone exerts on the remaining zones when it burns and expands. The success of this procedure is in large part a consequence of the fact that for much of the compression stroke the chemistry is inactive and thus has little influence on fluid mechanics and heat transfer. Then, when chemistry is active, combustion is rather sudden, leaving little time for interaction between chemistry and fluid mixing and heat transfer. HCCI combustion is in general too fast for effects such as heat transfer or diffusion to significantly affect combustion.

\section{Model Validation}

The methodology has been applied to recent experimental results for propane. The results have been obtained in a modified Cummins $C$ engine. This is a 6-cylinder engine that has been modified to run on a single cylinder in HCCI mode. The engine characteristics are listed in Table 1. Three operating conditions are being analyzed. These are named Case 1, Case 2, and Case 3, and are described in Table 2. Cases 1 and 2 are essentially the same operating conditions, except that the inlet temperature in Case 1 is $12 \mathrm{~K}$ higher than in Case 2. Due to the high sensitivity of HCCI combustion to temperature, Case 1 burns $4^{\circ}$ earlier than Case 2. Cases 1 and 2 are very lean operating conditions $(\phi=0.17)$. Case 3 corresponds to a late combustion event (peak of heat release at $8^{\circ}$ ATDC). Fuel and air are mixed well upstream of the engine, so that the incoming mixture can be considered homogeneous. The residual gas fraction is of the order of $1 \%$.

A detailed grid has been constructed to model the Cummins $\mathrm{C}$ engine cylinder. This is a 2 -dimensional grid with 160,000 elements. Wall elements were built with a $50-\mu \mathrm{m}$ thickness to obtain adequate resolution. A sensitivity analysis of the mesh was done, 
which indicated that little gain was obtained by further refining the mesh. The very dense mesh used improves the quality of the results, but also increases the computational time required for a run to about 30 hours in a DEC Alpha $450 \mathrm{MHz}$ workstation. Of all the crevices existing in the engine, only the ring crevice was resolved. For the KIVA3V runs, the temperatures for the cylinder wall, head and piston are considered constant and uniform $(422 \mathrm{~K}, 478 \mathrm{~K}$ and $437 \mathrm{~K}$ respectively). These temperatures were determined with a thermodynamic model similar to that described in [13].

The KIVA3V results are then processed according to the procedure previously described and fed into HCT. HCT is run with a chemistry mechanism that includes species through $\mathrm{C}_{4}$ [14]. This mechanism also includes $\mathrm{NO}_{\mathrm{x}}$ kinetics [15]. The chemical kinetic reaction mechanisms used by the model for natural gas ignition and $\mathrm{NO}_{\mathrm{x}}$ production have been extremely well established and are widely used. The reaction mechanism includes 179 chemical species and 1125 chemical reactions. A 10-zone HCT run typically takes about 12 hours in the DEC Alpha. Total running time for KIVA3V-HCT is of the order of 40 hours.

The results of the analysis are shown in Figures 1 through 5. Figure 1(a) shows the temperature distribution obtained from KIVA3V for Case 1 at $5^{\circ}$ BTDC. Temperatures are shown on a gray scale. The grid is too dense to be displayed in this figure. Figure 1(b) shows the mass temperature distribution for Case 1 , at $5^{\circ}$ BTDC. The figure also shows the temperature distribution of the zones, and the average temperature for each zone. Figure 1(c) shows the temperature history of the 10 zones as a function of crank angle, for Case 1 . The figure shows the point $\left(6^{\circ} \mathrm{BTDC}\right)$ at which $5 \%$ of the total available heat release has occurred. At this point, the KIVA3V temperature distributions are abandoned and are replaced by HCT with the Woschni heat transfer correlation. This point is indicated by a line and a sudden change in the slope of the temperature histories. At this moment, the central core zone (zone 10) starts to react. Zone 10 expands due to heat release, compressing and heating the remaining zones. This compression work heats the other zones enough to make some of them (6-9) react to near completion. Zones react in succession, from hot to cold, with a kinetics-controlled time lag between the successive zones. This time lag increases the burn duration compared to the result that would be obtained if the entire mixture were isothermal. The fact that an isothermal charge burns very quickly has been discussed in previous papers $[16,17]$, where it was observed that a single-zone model predicts an almost instantaneous combustion.

Figures 1(d) and 2 show mole fraction of different species during HCCI ignition, for zone 10 (central core) of Case 1. Figure 1(d) shows mole fraction of fuel (propane), NO, and radicals $\mathrm{OH}, \mathrm{H}_{2} \mathrm{O}_{2}$, and $\mathrm{H}$. The figure shows that, at the point of ignition, the $\mathrm{H}_{2} \mathrm{O}_{2}$ generated during low temperature heat release is suddenly converted to $\mathrm{OH}$, which rapidly consumes the fuel. The figure also shows that very little $\mathrm{NO}_{\mathrm{x}}$ is generated. Nearly all of the $\mathrm{NO}_{\mathrm{x}}$ produced is generated after the combustion event, when the central core reaches its maximum temperature due to recompression caused by ignition of other zones. 
Figure 2 shows mole fraction of fuel, intermediate hydrocarbons (propene, $\mathrm{C}_{3} \mathrm{H}_{6}$; formaldehyde, $\mathrm{CH}_{2} \mathrm{O}$; and acetaldehyde, $\mathrm{CH}_{3} \mathrm{CHO}$ ) and carbon monoxide. The figure shows that the fuel and intermediate hydrocarbons are decomposed very suddenly at the time of ignition. Decomposition of hydrocarbons forms carbon monoxide. Carbon monoxide concentration grows for as long as hydrocarbons remain in the combustion chamber. When all hydrocarbons are consumed, carbon monoxide is then oxidized to produce $\mathrm{CO}_{2}$. Oxidation of $\mathrm{CO}$ is slow compared to oxidation of hydrocarbons.

Figure 3 shows a comparison between experimental pressure traces and calculated pressure traces for the three cases being considered. Experimental pressure traces in Figure 3 are 100-cycle averages. HCCI combustion has the important characteristic of having extremely low cycle-to-cycle variation. In the three cases analyzed here, repeatability is so good that the average pressure trace is almost identical to the pressure traces for the individual cycles. The coefficients of variation in gross imep for Cases 1,2 and 3 are respectively $1.2 \%, 1.5 \%$ and $0.8 \%$. Figure 3 shows an almost perfect agreement between experimental and numerical pressure traces for Cases 1 and 3 . The agreement holds during the compression stroke as well as during the expansion stroke. In Case 2 the analysis underpredicts the experimental peak cylinder pressure by 9.3 bar (149.7 vs. 159).

Figure 4 shows a comparison between experimental and numerical apparent heat release rates. The figure shows an excellent agreement. The analysis does an excellent job at predicting the shape of the heat release rate, as well as the peak heat release rate. Heat release rate is typically difficult to match analytically because heat release rate is obtained by analyzing pressure traces according to the first law of thermodynamics [18]. Small inaccuracies in pressure can therefore result in great differences in apparent heat release rates. Accurate prediction of heat release rates is possible for HCCI combustion because HCCI combustion is relatively insensitive to turbulence. Turbulence, flame propagation and mixing make SI and CI combustion much more difficult to predict with good accuracy than HCCI combustion.

Figure 5 shows a comparison between experimental and numerical results for the main combustion parameters of $\mathrm{HCCI}$, for the three cases being analyzed. The figure shows that the results for maximum pressure, burn duration, indicated efficiency and combustion efficiency match very closely the experimental results (listed in Table 2). The maximum error for these parameters is $8 \%$ for the burn duration, and the average error is significantly lower than that $(3 \%)$.

Our methodology, as implemented here, is expected to underestimate hydrocarbon emissions. The reason is that only the ring crevice is included in the grid. Other crevices exist in the engine that contribute additional hydrocarbons. In this case, the analysis underpredicts $\mathrm{HC}$ emissions by $20-30 \%$ for Cases 1 and 3. For Case 2 the agreement is almost perfect, although this may be due to the fact that for Case 2 the analysis also underpredicts the peak cylinder pressure. For Cases 1 and 3, $\mathrm{CO}$ emissions are underpredicted by 50-70\%. For Case 2, $\mathrm{CO}$ emissions are predicted almost perfectly. Carbon monoxide emissions are intrinsically difficult to predict. During combustion, $\mathrm{CO}$ is an intermediate combustion product. Fuel is first converted into intermediate 
hydrocarbons, which then react to form $\mathrm{CO}$. Carbon monoxide finally reacts with $\mathrm{OH}$ to generate $\mathrm{CO}_{2}$ after all the hydrocarbons are consumed $(\mathrm{OH}$ reacts with hydrocarbons much faster than with $\mathrm{CO}$, see Figure 2). Considering the intrinsic difficulty in predicting $\mathrm{CO}$ emissions in HCCI combustion, it is remarkable that the method yields reasonable estimates of $\mathrm{CO}$ emissions.

Figure 5 does not show a comparison between values of experimental and predicted $\mathrm{NO}_{\mathrm{x}}$ emissions. The reason for this is that both are extremely low. $\mathrm{NO}_{\mathrm{x}}$ emissions are only a few parts per million for the three cases (see Table 2). These values are so low that they are difficult to measure accurately with conventional experimental equipment. They are also hundreds of times less than generated in a diesel engine. The low emission of $\mathrm{NO}_{\mathrm{x}}$ is one of the main reasons for exploring HCCI combustion.

\section{The Heat Transfer Correlation}

The sequential methodology described in this paper uses the Woschni correlation [12] to calculate heat transfer coefficients after ignition (before ignition, heat transfer is calculated by KIVA3V). Use of the Woschni correlation for HCCI combustion introduces errors in the analysis, because the Woschni correlation was derived for diesel engines, where radiation heat transfer is important. Using the Woschni correlation for HCCI engines may therefore overestimate the heat transfer coefficient [19]. Considering the inaccuracy of the Woschni correlation, it is important to conduct a sensitivity analysis on the effect of the heat transfer correlation on the results of the analysis. The sensitivity analysis is conducted here by repeating the calculation for Cases 1,2 and 3, with the only difference that the Woschni correlation is not used. Instead, the process is considered adiabatic after ignition. Before ignition, KIVA3V is still used in both cases to determine the effect of heat transfer. Considering that heat transfer during HCCI combustion is likely to fall between the Woschni heat transfer and no heat transfer at all, analyzing these two extremes yields an estimate of the maximum possible error that results from the use of an inaccurate heat transfer correlation.

The results are shown in Figures 6 and 7. Figure 6 shows pressure traces calculated for Cases 1, 2 and 3, both with the Woschni correlation and with no heat transfer correlation (considering adiabatic conditions after ignition). The figure shows a very small difference between the adiabatic and Woschni calculations. For Cases 1 and 2, there is no noticeable difference in pressure until after the peak cylinder pressure has been reached. By this time, combustion is very close to complete (see Figure 4), so heat transfer has very little effect on HCCI combustion. For Case 3, heat transfer has some effect in delaying ignition with respect to the adiabatic case, but even in this case heat transfer has little effect on the peak cylinder pressure and on the shape of the pressure trace.

Figure 7 shows the ratio between the results obtained with the adiabatic calculation and the results obtained with the Woschni correlation for the main HCCI combustion parameters. The figure shows that peak cylinder pressure, burn duration and combustion 
efficiency are affected very little by heat transfer. These parameters are unaffected by heat transfer because they are determined by the main combustion event, which is very sudden. Figure 4 indicates that most of the combustion event takes place within 5 crank angle degrees from the point of ignition. This interval is so short that heat transfer does not have time to significantly affect HCCI combustion. Therefore, peak cylinder pressure, burn duration and combustion efficiency can be accurately predicted, even if an inaccurate heat transfer correlation is being used.

Figure 7 shows that indicated efficiency and $\mathrm{HC}$ and $\mathrm{CO}$ emissions are sensitive to heat transfer. This is because these parameters are not completely determined during the main combustion event. Instead, they are affected by the conditions that exist in the cylinder well after the point of ignition, so that heat transfer has more time to have an effect on them. Indicated efficiency is affected by heat transfer during the whole expansion stroke. Heat transfer reduces the pressure during the expansion stroke, therefore resulting in a higher indicated efficiency for the adiabatic case compared to the Woschni case. Emissions of $\mathrm{HC}$ and $\mathrm{CO}$ are sensitive to heat transfer because there is always a fraction of the mass inside the cylinder (zone 5 in these cases) that is very near the ignition temperature. A very small temperature change due to heat transfer is enough to make a significant difference in the chemical heat release (and therefore the emissions) from this zone. In addition to this, ignition of zone 5 occurs well after the main combustion event, so heat transfer has more time to play a role. This extreme sensitivity of $\mathrm{HC}$ and $\mathrm{CO}$ emissions to external conditions stresses once more the difficulty in obtaining good predictions for emissions during HCCI combustion.

The sensitivity analysis presented here demonstrates that HCCI combustion is too fast for heat transfer to play an important role. A heat transfer correlation can be used after ignition (KIVA3V is used before ignition) to make accurate predictions of peak cylinder pressure, burn duration and combustion efficiency, even if the heat transfer correlation is quite inaccurate. Indicated efficiency and $\mathrm{HC}$ and $\mathrm{CO}$ emissions are more sensitive to the heat transfer correlation being used. However, it must be kept in mind that the sensitivity analysis presented here has compared two extreme cases: the Woschni correlation and an adiabatic case. Therefore, actual errors obtained from the use of an inaccurate heat transfer correlation are expected to be only a fraction of the relative differences shown in Figure 7.

\section{Evaluation of Potential Methodologies for $\mathrm{HC}$ and $\mathrm{CO}$ Emission Reductions}

The purpose of a good model is to reduce the need for experimentation.

In this section, our model is applied to evaluate four possible design and operation modifications to the engine as techniques for reducing $\mathrm{HC}$ and $\mathrm{CO}$ emissions in an $\mathrm{HCCI}$ engine. High hydrocarbon and $\mathrm{CO}$ emissions are a disadvantage of HCCI combustion. While it is possible to use an oxidizing catalytic converter to reduce these emissions 
$[20,21]$, it is clearly desirable to increase the amount of the fuel that burns inside the cylinder to increase engine efficiency. The four techniques being evaluated are:

1. Low swirl. Swirl enhances heat transfer, and therefore it may extend the boundary layer thickness, increasing the amount of cold mass, and increasing $\mathrm{CO}$ and $\mathrm{HC}$ emissions. For these runs, swirl is reduced from the original value (4.3) to a tenth of the original value (0.43). All other conditions remain unchanged.

2. Hot walls. The wall temperature was increased from the original values (wall at 422 $\mathrm{K}$, head at $437 \mathrm{~K}$ and piston at $478 \mathrm{~K}$ ) to $600 \mathrm{~K}$ to evaluate the effect of having hot wall conditions in the chamber. All other conditions remain the same.

3. Crevices. Previous work [7] found that crevices were responsible for a good part of the hydrocarbon emissions. Here we consider an engine with no crevices and the same compression ratio (18:1) and displacement as the original engine. All other engine parameters also remain the same.

4. All. The fourth technique is a combination of the previous three. An engine is considered with $600 \mathrm{~K}$ walls, no crevices and low (0.43) swirl.

The simplest way to compare these four techniques is to consider that the four are applied with the same temperature at intake valve closing. However, starting with the same initial temperature for all techniques results in advanced combustion for some cases. Since combustion timing plays a major role in determining $\mathrm{HC}$ and $\mathrm{CO}$ emissions in $\mathrm{HCCI}$ combustion, it is important to establish how much of the change in emissions is due to the change in ignition timing, and how much is due to the emission reduction technique being considered. Therefore, a second condition is evaluated in which the temperature at intake valve closing is adjusted to obtain ignition at the same time for all techniques. The analysis is done for Case 1 (see Table 2).

The results are presented in Figures 8,9 and 10. Figures 8 and 9 show the temperature mass distributions for Case 1 at $5^{\circ}$ BTDC, for the four techniques being considered, assuming that the four are applied with the same temperature at intake valve closing. Figures 8 and 9 also show the base-case mass distribution, (repeated from Figure 1(b)). Figure 8 shows that the temperature mass distribution with reduced swirl is very close to the base-case temperature mass distribution, although the low swirl case has a slightly lower fraction of mass at low temperatures (boundary layer), and a slightly higher peak cylinder temperature. Using an engine with a hot wall eliminates all the mass at temperatures under $630 \mathrm{~K}$. It also considerably increases the maximum temperature within the cylinder, resulting in earlier combustion.

Figure 9 shows the temperature mass distribution for an engine with no crevice, and also for an engine in which all three emission reduction techniques are applied (low swirl, hot wall and no crevice). The engine with no crevices has no mass at temperatures lower than $750 \mathrm{~K}$, indicating that most of the mass at temperatures lower than this is located in the crevices. The temperature mass distribution for this case is very narrow compared to the base-case. The maximum temperature in the cylinder is affected only slightly by the lack of crevices. The engine with low swirl, hot wall and low crevices (labeled "all" in the figure) has an extremely narrow temperature mass distribution. All of the mass for this 
case is located within $200 \mathrm{~K}$. The lack of mass at low temperature is certain to reduce HC and $\mathrm{CO}$ emissions, but the almost isothermal charge is likely to react very rapidly and produce a high peak cylinder pressure. The higher maximum temperature inside the cylinder results in earlier combustion than obtained in the base-case.

Figure 10 shows the results for the reduction in emissions in the HCCI engine, for Case 1. The figure shows ratios of the emissions calculated with the four $\mathrm{HC}$ and $\mathrm{CO}$ emission reduction techniques to the value of the base-case analysis results previously presented in this paper (see Table 2). Please notice that the ratios are not calculated with respect to the experimental results. The figure shows two sets of results. The first set is for the four cases having the same temperature at intake valve closing, and the second set is for the four cases having the same crank angle for ignition. Figure 10 shows the following results for each of the four techniques applied for reducing $\mathrm{HC}$ and $\mathrm{CO}$ emissions.

1. Reducing the swirl to $10 \%$ of the original value results in a $5 \%$ reduction in $\mathrm{CO}$ emissions. Reducing the swirl does not have any effect on HC emissions, because these originate at the crevices, where swirl does not play a significant role. Reducing the swirl does not significantly change the ignition timing, so the same results apply to the same temperature and same ignition angle cases.

2. Hot walls are especially effective in reducing $\mathrm{CO}$ emissions (by about $80 \%$ ), because $\mathrm{CO}$ emissions originate in the boundary layer. A hotter boundary layer results in lower $\mathrm{CO}$ emissions. Hot walls also reduce $\mathrm{HC}$ emissions by 55-75\%. For the hot wall case, the temperature at intake valve closing needs to be reduced by $35 \mathrm{~K}$ to obtain ignition at the same crank angle as in the base case.

3. An engine with no crevices has near zero $\mathrm{HC}$ emissions, since these originate mainly at the crevices [7]. Having no crevices also considerably reduces the $\mathrm{CO}$ emissions, by $90 \%$ for the same temperature case and by $80 \%$ for the same ignition point case. For the case with no crevices, the initial temperature has to be reduced by $15 \mathrm{~K}$ to obtain ignition at the same time as the base-case.

4. The engine with low swirl, hot wall and no crevice has near zero $\mathrm{HC}$ and $\mathrm{CO}$ emissions. At the near isothermal conditions existing in that case inside the cylinder, almost all of the fuel burns to completion in a very sudden combustion and high peak cylinder pressure. Only 5\% of the base-case CO emissions remain for the case with equal ignition angle, for which the initial temperature is $53 \mathrm{~K}$ lower than for the basecase.

\section{Conclusions}

A detailed fluid mechanics code and a detailed chemical kinetics code have been combined to produce accurate predictions for HCCI combustion and emissions. Instead of directly linking the two codes, the results of the fluid mechanics code are processed to create temperature histories that are then fed into the chemical kinetics code. The advantage of this procedure is that a small number of zones (10) is enough to obtain accurate results. This procedure yields all of the benefits of directly linking the two codes 
with a much-reduced computational intensity, which makes the problem accessible to current computers. The success of this procedure is in large part a consequence that, for much of the compression stroke, the chemistry is inactive and thus has little influence on fluid mechanics and heat transfer. Then, when chemistry is active, combustion is rather sudden, leaving little time for interaction between chemistry and fluid mixing and heat transfer.

The predictions from the analysis have been compared to recent experimental results for propane HCCI combustion. The analysis does an excellent job at predicting all combustion parameters. Maximum pressure, burn duration, indicated efficiency and combustion efficiency are matched to within an average error of 3\%. Pressure traces are matched very closely for the whole operating cycle. The agreement is good even for parameters that are intrinsically difficult to match, such as $\mathrm{HC}$ and $\mathrm{CO}$ emissions and heat release rates.

The paper analyzes the sensitivity of the results to the use of a heat transfer correlation that is known to be in need of improvement. The results show that HCCI combustion is too sudden for the heat transfer correlation to have an effect on the main combustion event. Good results for HCCI combustion can therefore be obtained, even if the heat transfer correlation is inaccurate. The heat transfer correlation does have a more significant effect on indicated efficiency and $\mathrm{HC}$ and $\mathrm{CO}$ emissions.

The paper demonstrates the power of the model through a numerical study on how parameters such as swirl rate, crevices and ceramic walls could help in reducing HC and $\mathrm{CO}$ emissions from HCCI engines. Combining the three methodologies (operating an engine with low swirl, no crevices and hot walls) reduces $\mathrm{HC}$ and $\mathrm{CO}$ emissions to near zero.

\section{Acknowledgments}

This project is funded by DOE, Office of Transportation Technologies, Steve Goguen and Gurpreet Singh, program managers. Work performed under the auspices of the U.S. Department of Energy by Lawrence Livermore National Laboratory under Contract W7405-ENG-48.

\section{References}

1. Suzuki, H., Koike, N., Ishii, H., and Odaka, M., "Exhaust Purification of Diesel Engines by Homogeneous Charge with Compression Ignition Part 1: Experimental Investigation of Combustion and Exhaust Emission Behavior Under Pre-Mixed Homogeneous Charge Compression Ignition Method," SAE paper 970313, 1997. 
2. Ishibashi, Y., and Asai, M., "Improving the Exhaust Emissions of Two-Stroke Engines by Applying the Activated Radical Concept," SAE Paper 960742. 1996.

3. Kimura, S., Aoki, O., Ogawa, H., Muranaka, S., Enomoto, Y., "New Combustion Concept for Ultra-Clean and High-Efficiency Small DI Diesel Engines," SAE Paper 1999-01-3681, 1999.

4. Najt, P. M. and Foster, D. E., "Compression-Ignited Homogeneous Charge Combustion," SAE paper 830264, 1983.

5. Noguchi, M., Tanaka, Y., Tanaka, T., and Takeuchi, Y., “A Study on Gasoline Engine Combustion by Observation of Intermediate Reactive Products During Combustion," SAE paper 790840, 1979.

6. Iida, N., "Alternative Fuels and Homogeneous Charge Compression Ignition Combustion Technology," SAE paper 972071, 1997.

7. Aceves, S. M., Flowers, D.L., Westbrook, C.K., Smith, J. R., Pitz, W.J., Dibble, R., Christensen, M. and Johansson, B., "A Multi-Zone Model for Prediction of HCCI Combustion and Emissions," SAE Paper 2000-01-0327, 2000.

8. Amsden, A.A., "KIVA-3: A KIVA Program with Block-Structured Mesh for Complex Geometries," Los Alamos National Laboratory Report LA-12503-MS, 1993.

9. Lund, C. M., "HCT - A General Computer Program for Calculating Time-Dependent Phenomena Involving One-Dimensional Hydrodynamics, Transport, and Detailed Chemical Kinetics," Lawrence Livermore National Laboratory report UCRL-52504, 1978.

10. Akagawa, H., Miyamoto, T., Harada, A., Sasaki, S., Shimazaki, N., Hashizuma, T., and Tsujimura, K, "Approaches to Solve Problems of the Premixed Lean Diesel Combustion," SAE paper 1999-01-0183, 1999.

11. Iida, N., Ichikura, T., Kase, K., and Enomoto, Y., "Self-Ignition and Combustion Stability in a Methanol Fueled Low Heat Rejection Ceramic ATAC EngineAnalysis of Cyclic Variation at High Wall Temperatures and Lean Burn Operation," Society of Automotive Engineers of Japan paper 9733684, 1997.

12. Woschni, G., "Universally Applicable Equation for the Instantaneous Heat Transfer Coefficient in the Internal Combustion Engine," SAE Paper 670931, 1967.

13. Watson, N. and Marzouk, M. "A Non-Linear Digital Simulation of Turbocharged Diesel Engines Under Transient Conditions”, SAE Paper 770123, 1977. 
14. Curran, H. J., Gaffuri, P., Pitz, W. J., Westbrook, C. K., and Leppard, W. R., "Autoignition Chemistry of the Hexane Isomers: An Experimental and Kinetic Modeling Study," SAE paper 952406, 1995.

15. Frenklach, M.,Wang, H., Goldenberg, M., Smith G. P., Golden, D. M., Bowman, C. T., Hanson, R. K., Gardiner, W. C., and Lissianski, V., "GRI-Mech - An Optimized Detailed Chemical Reaction Mechanism for Methane Combustion", GRI Topical Report No. GRI-95/0058, 1995.

16. Aceves, S.M., Smith, J.R., Westbrook, C., and Pitz, W. "Compression Ratio Effect on Methane HCCI Combustion," ASME Journal of Engineering for Gas Turbines and Power, Vol. 121, pp. 569-574, 1999.

17. Flowers, D. L., Aceves, S. M., Westbrook, C. K., Smith, J.R., and Dibble, R. W., "Sensitivity of Natural Gas HCCI Combustion to Fuel and Operating Parameters Using Detailed Kinetic Modeling," In AES-Vol. 39, "Proceedings of the ASME Advanced Energy Systems Division - 1999," Edited by S.M. Aceves, S. Garimella and R. Peterson, pp. 465-473, 1999.

18. Heywood, J. B., Internal Combustion Engine Fundamentals, McGraw-Hill, Inc., New York, NY, 1988.

19. Fiveland, S.B., and Assanis, D.N., "A Four-Stroke Homogeneous Charge Compression Ignition Engine Simulation for Combustion and Performance Studies," SAE Paper 2000-01-0332, 2000.

20. Iwabuchi, Y., Kawai, K., Shoji, T., and Takeda, Y., "Trial of New Concept Diesel Combustion System - Premixed Compression-Ignition Combustion," SAE Paper 1999-01-0185, 1999.

21. Erlandsson, O., Johansson, B., and Silversand, F.A., "Hydrocarbon (HC) Reduction of Exhaust Gases from a Homogeneous Charge Compression Ignition (HCCI) Engine Using Different Catalytic Mesh-Coatings," SAE Paper 2000-01-1847, 2000. 


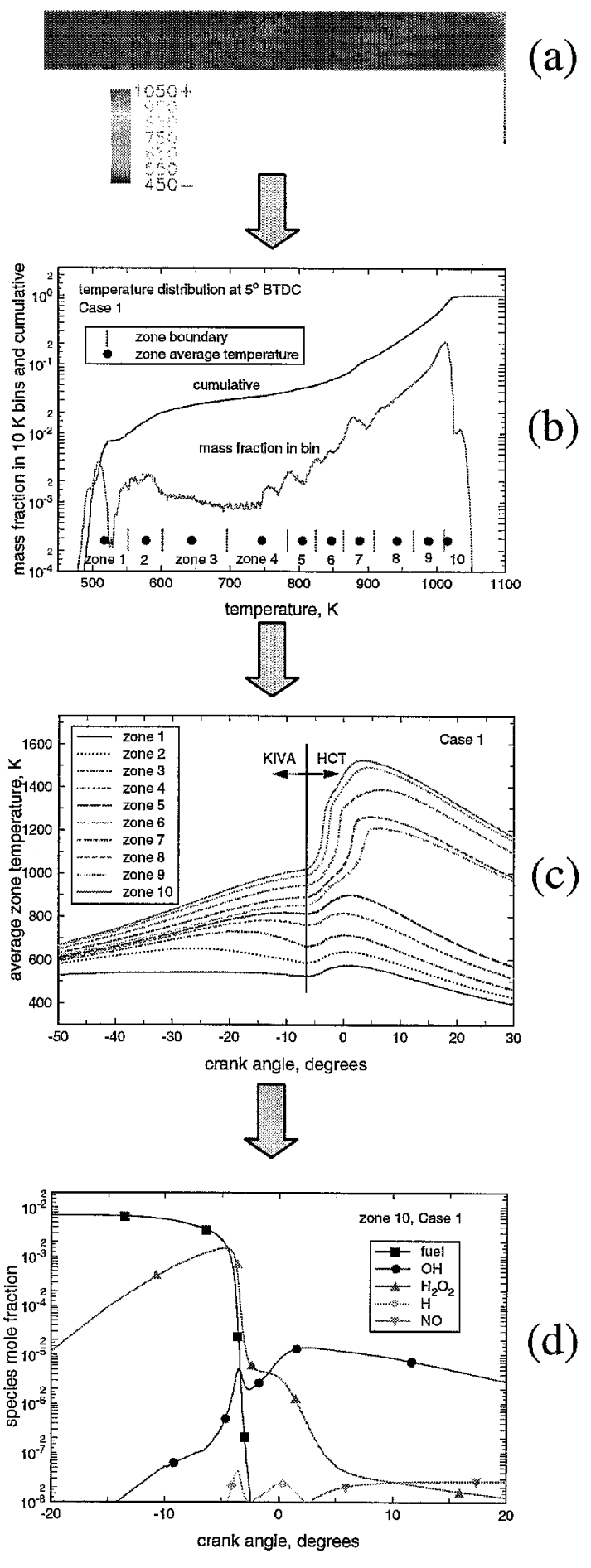

Figure 1. The main steps in the sequential multi-zone analysis of HCCI combustion. (a) Calculation of temperatures inside the cylinder from KIVA3V. (b) Calculation of mass distribution as a function of temperature. (c) Calculation of temperature histories for the zones. (d) Detailed chemical kinetics HCT run with temperature histories determined from KIVA3V. 
Table 1. Main characteristics of the Cummins $\mathrm{C}$ single cylinder engine used for the HCCI experiments.

\begin{tabular}{|l|l|}
\hline Displaced volume & $1378 \mathrm{~cm}^{3}$ \\
\hline Bore & $114 \mathrm{~mm}$ \\
\hline Stroke & $135 \mathrm{~mm}$ \\
\hline Connecting rod length & $216 \mathrm{~mm}$ \\
\hline Geometric compression ratio & $18: 1$ \\
\hline Exhaust valve open & $135^{\circ}$ ATDC \\
\hline Exhaust valve close & $370^{\circ}$ ATDC \\
\hline Intake valve open & $350^{\circ}$ ATDC \\
\hline Intake valve close & $574^{\circ}$ ATDC \\
\hline Geometry & $\begin{array}{l}\text { Flat top piston and } \\
\text { head }\end{array}$ \\
\hline
\end{tabular}

Table 2. Main HCCI combustion characteristics of the three cases selected for analysis.

\begin{tabular}{|l|l|l|l|}
\hline & Case 1 & Case 2 & Case 3 \\
\hline Engine speed, rpm & 1002 & 1001 & 1800 \\
\hline Intake temperature, $\mathrm{K}$ & 352.3 & 340.2 & 341.6 \\
\hline $\begin{array}{l}\text { Absolute intake pressure, } \\
\text { bar }\end{array}$ & 2.72 & 2.75 & 1.88 \\
\hline Equivalence ratio & 0.17 & 0.17 & 0.36 \\
\hline Swirl ratio & 4.3 & 4.3 & 4.3 \\
\hline Peak cylinder pressure, bar & 165.49 & 158.6 & 120.9 \\
\hline CAD for peak heat release & $-3.5 \mathrm{ATDC}$ & $0.5 \mathrm{ATDC}$ & $8.0 \mathrm{ATDC}$ \\
\hline burn duration, CAD & 11.5 & 13.0 & 9.0 \\
\hline Combustion efficiency, \% & 89.4 & 82.6 & 93.1 \\
\hline Gross IMEP, bar & 4.7 & 4.5 & 6.45 \\
\hline $\begin{array}{l}\text { Gross indicated efficiency, } \\
\%\end{array}$ & 41.4 & 38.4 & 38.9 \\
\hline $\mathrm{HC}$ emissions, g/kg fuel & 59.32 & 72.45 & 63.88 \\
\hline CO emissions, g/kg fuel & 232.6 & 510.21 & 25.41 \\
\hline $\mathrm{NO}_{\mathrm{x}}$ emissions, g/kg fuel & 0.18 & 0.18 & 0.51 \\
\hline $\mathrm{NO}_{\mathrm{x}}$ emissions, ppm & 1.9 & 1.9 & 11.4 \\
\hline
\end{tabular}

1. Burn duration is defined as the crank angle between the two points at which apparent heat release is $10 \%$ of the peak heat release. 


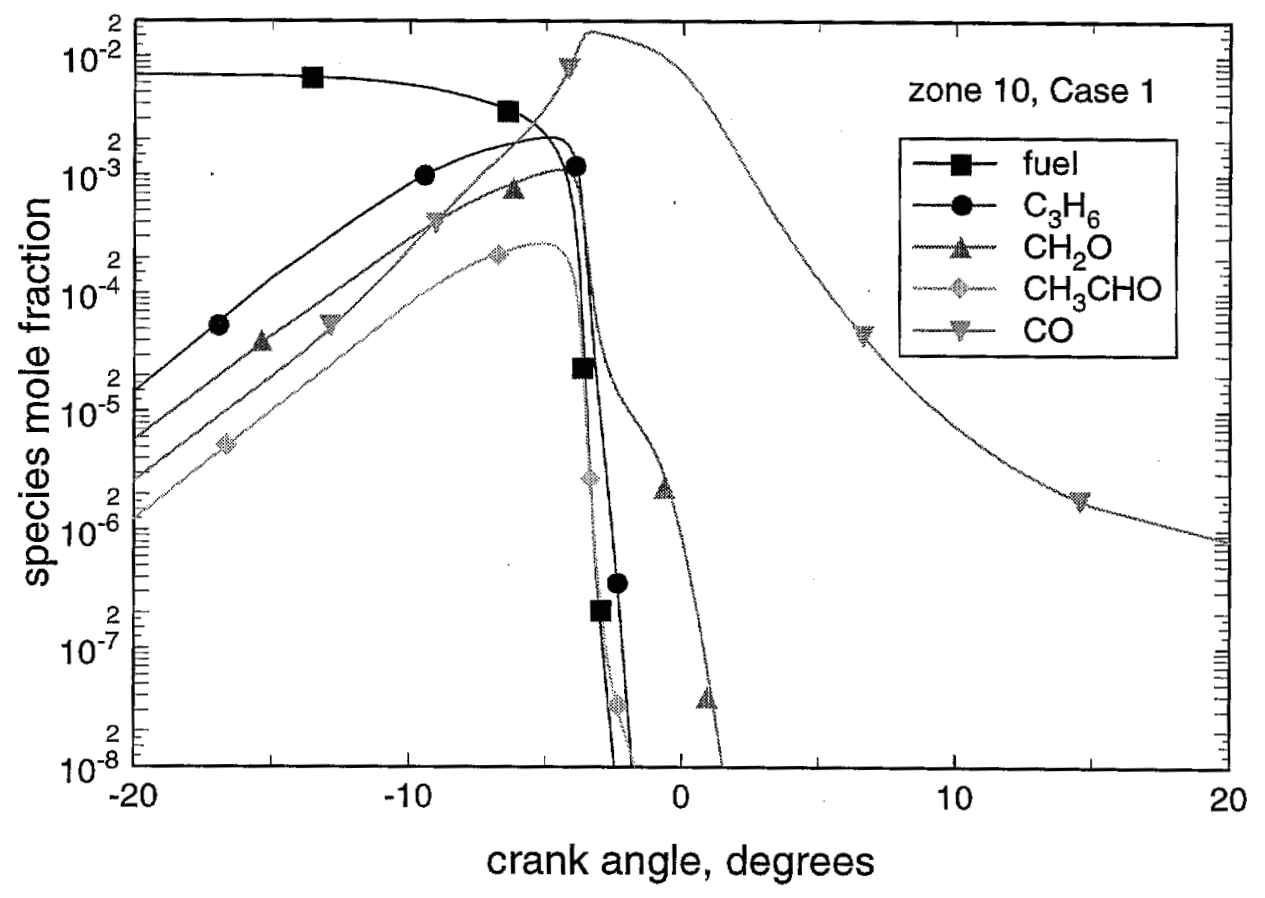

Figure 2. Mole fraction of fuel, intermediate hydrocarbons (propene, $\mathrm{C}_{3} \mathrm{H}_{6}$; formaldehyde, $\mathrm{CH}_{2} \mathrm{O}$; and acetaldehyde, $\mathrm{CH}_{3} \mathrm{CHO}$ ) and carbon monoxide, for zone 10 (central core) of Case 1 during the period of $\mathrm{HCCI}$ ignition. 


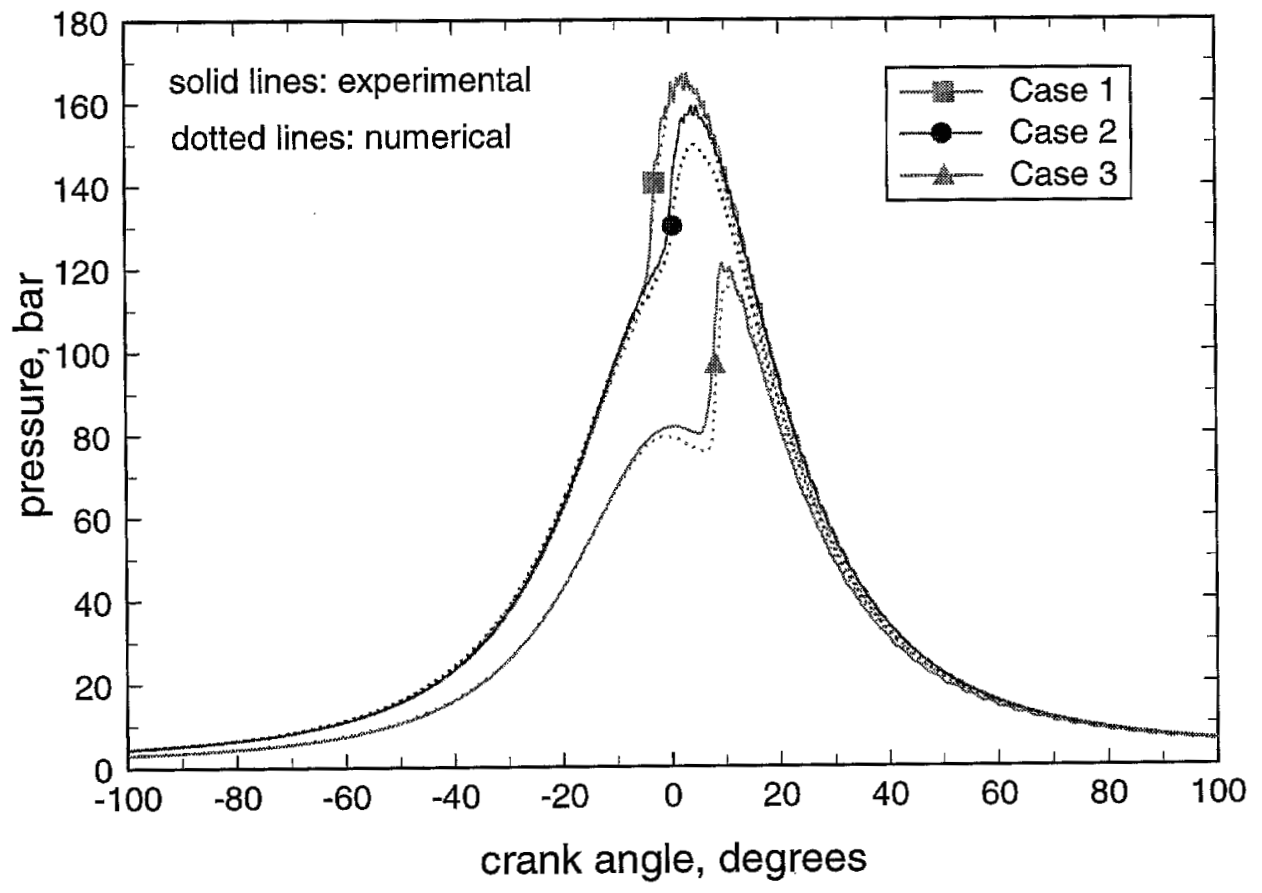

Figure 3. Experimental and numerical pressure traces for the three cases being considered in this paper. Dotted lines represent numerical results and solid lines show experimental results. 


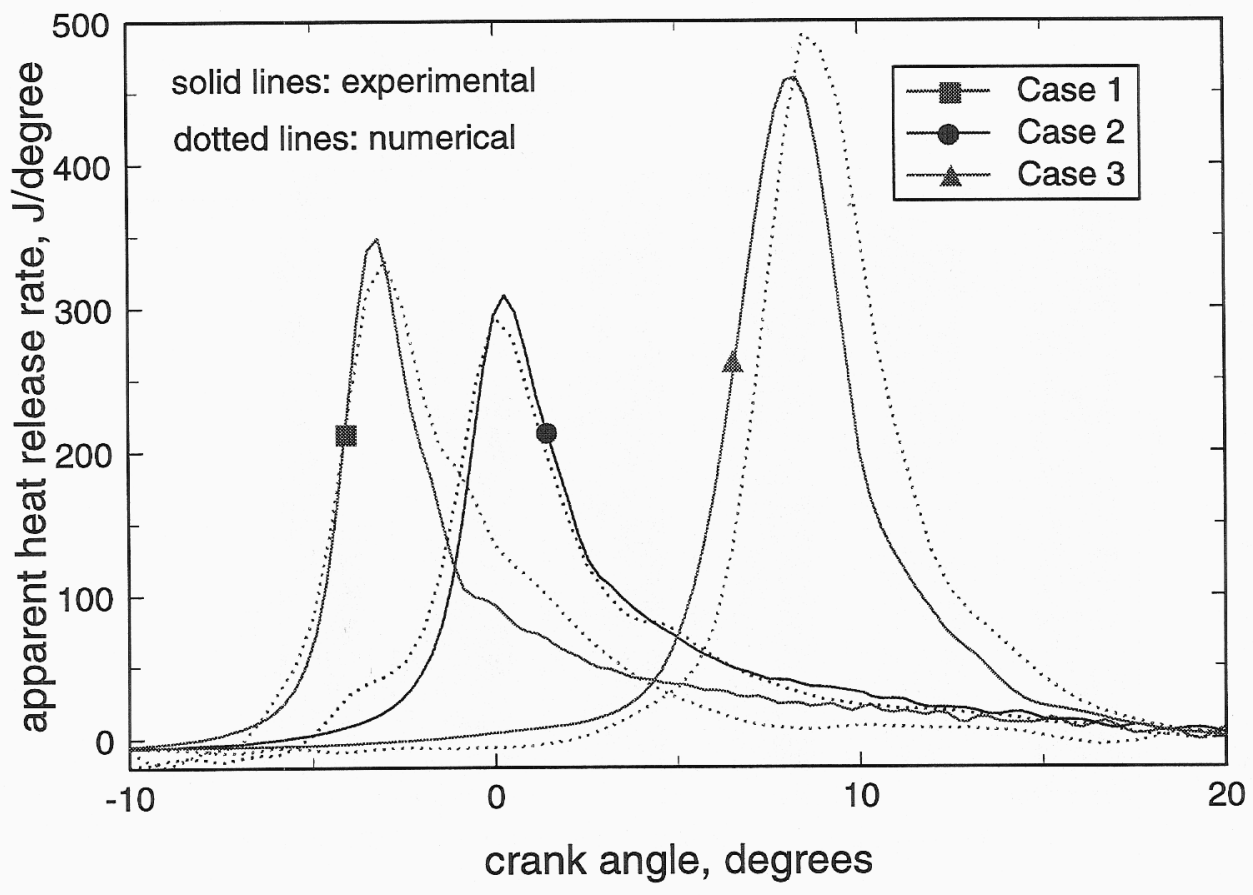

Figure 4. Experimental and numerical apparent heat release rates for the three cases being considered in this paper. Dotted lines represent numerical results and solid lines show experimental results. 


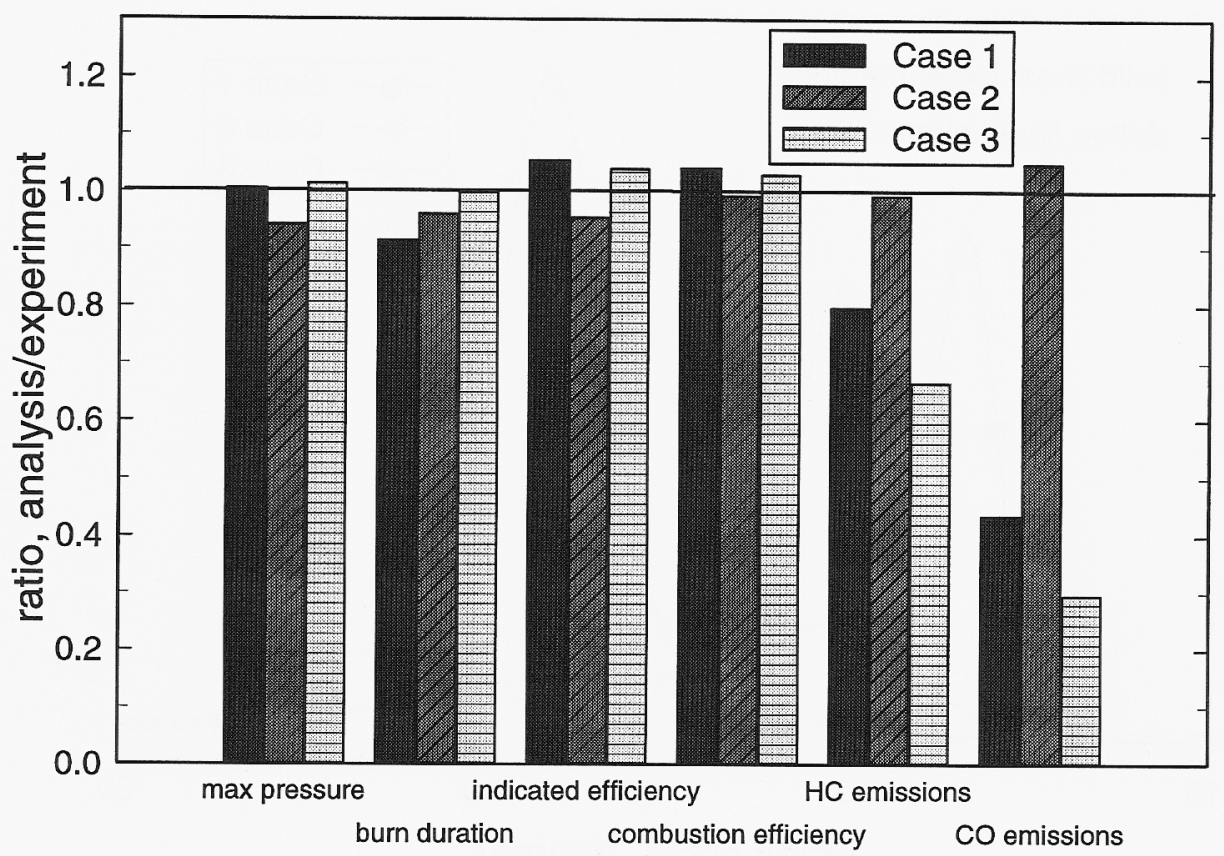

Figure 5. Comparison between experimental and numerical results for the main combustion parameters of $\mathrm{HCCI}$, for the three cases being analyzed. The figure shows the ratio between numerical and experimental values for peak cylinder pressure, burn duration (crank angle between the two points at which apparent heat release is $10 \%$ of the peak heat release), indicated efficiency, combustion efficiency, and $\mathrm{HC}$ and $\mathrm{CO}$ emissions. 


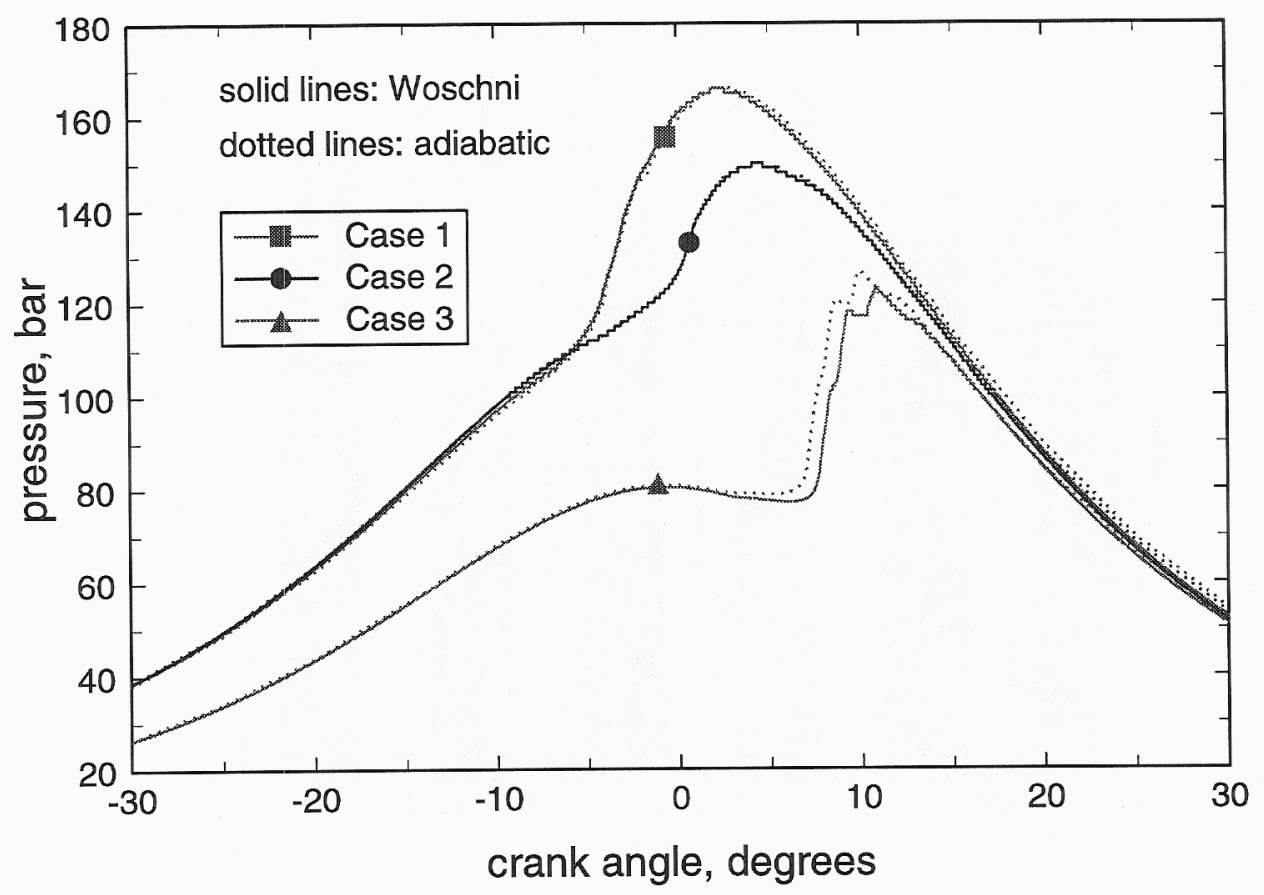

Figure 6. Pressure traces calculated for Cases 1, 2 and 3, both with the Woschni correlation and with no heat transfer correlation (adiabatic after ignition). The heat transfer correlations are only used after HCCI ignition. Before ignition, heat transfer is calculated by KIVA for both cases. 


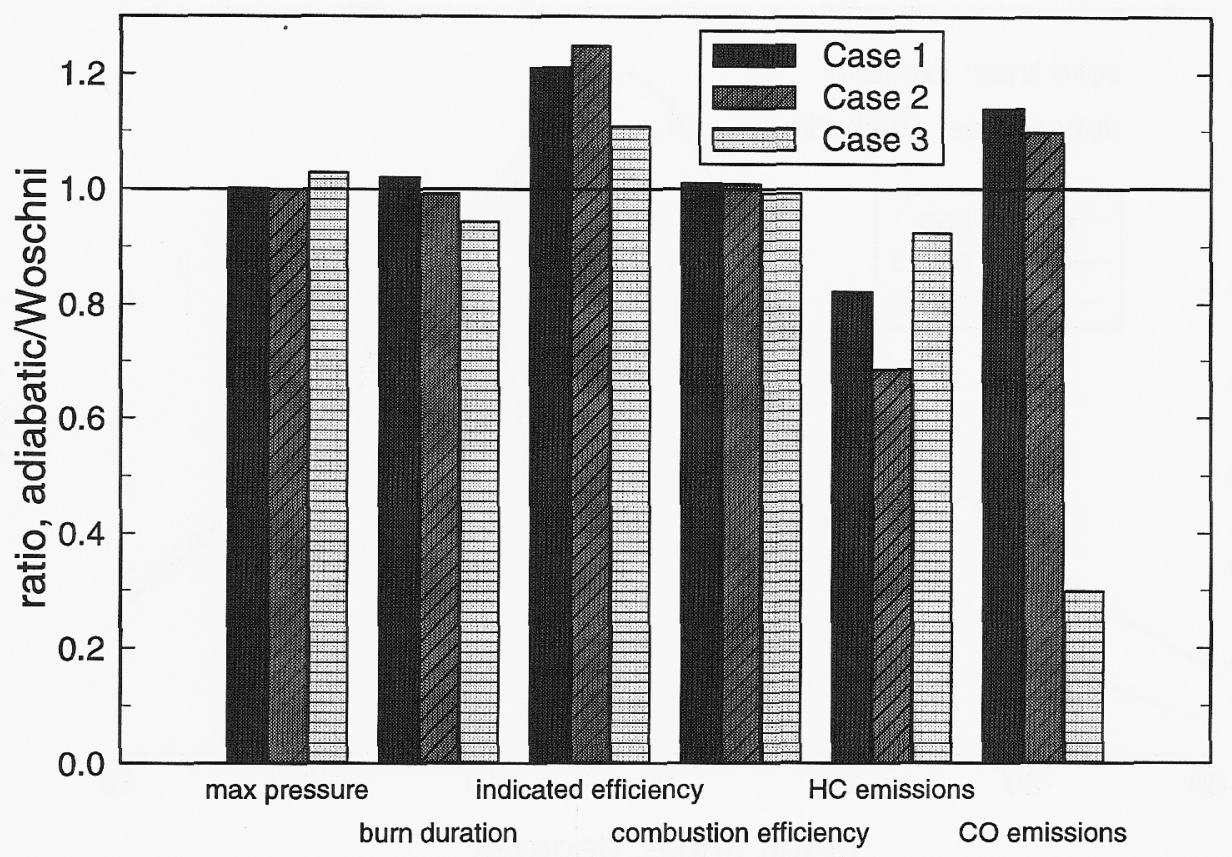

Figure 7. Ratio between the results obtained with the adiabatic calculation and the results obtained with the Woschni correlation for the main HCCI combustion parameters. The heat transfer correlations are only used after HCCI ignition. Before ignition, heat transfer is calculated by KIVA for both cases. 


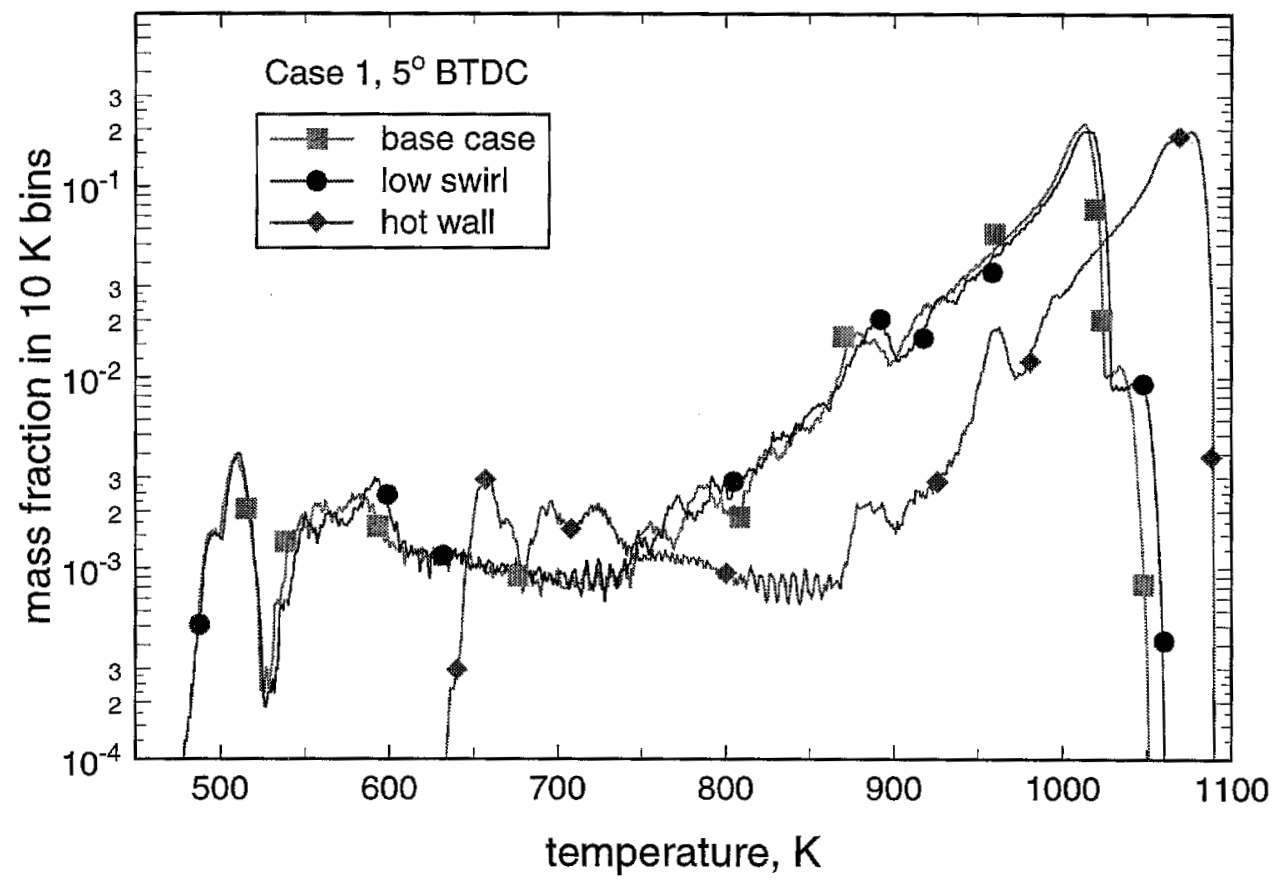

Figure 8. Temperature mass distributions for Case 1 at $5^{\circ} \mathrm{BTDC}$, for an engine with low swirl and an engine with hot $(600 \mathrm{~K})$ walls, compared to the base-case mass distribution (repeated from Figure 1(b)). All cases start with the same temperature at intake valve closing. 


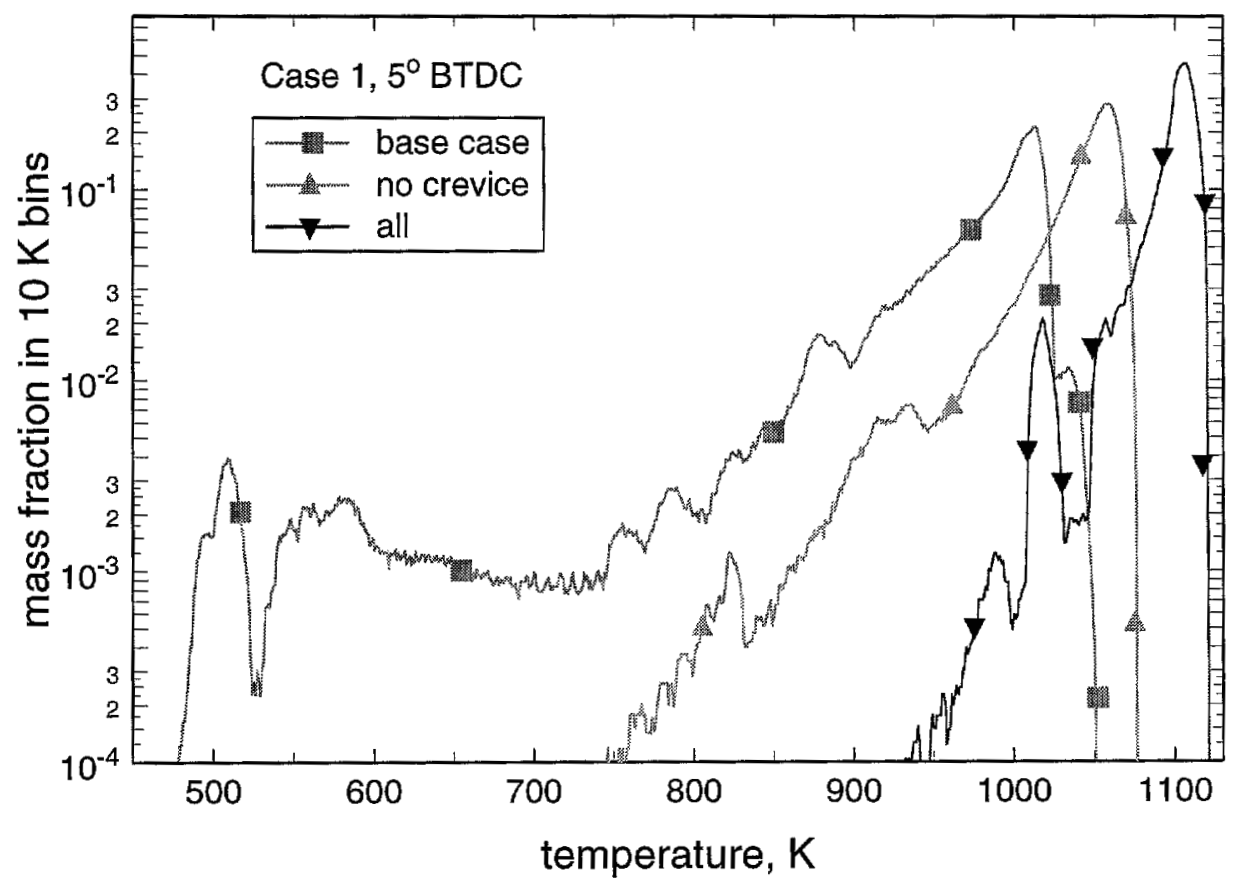

Figure 9. Temperature mass distributions for Case 1 at $5^{\circ}$ BTDC, for an engine with no crevices, and for an engine with low swirl, hot $(600 \mathrm{~K})$ walls and no crevices (labeled "all" in the figure) compared to the base-case mass distribution (repeated from Figure 1(b)). All cases start with the same temperature at intake valve closing. 


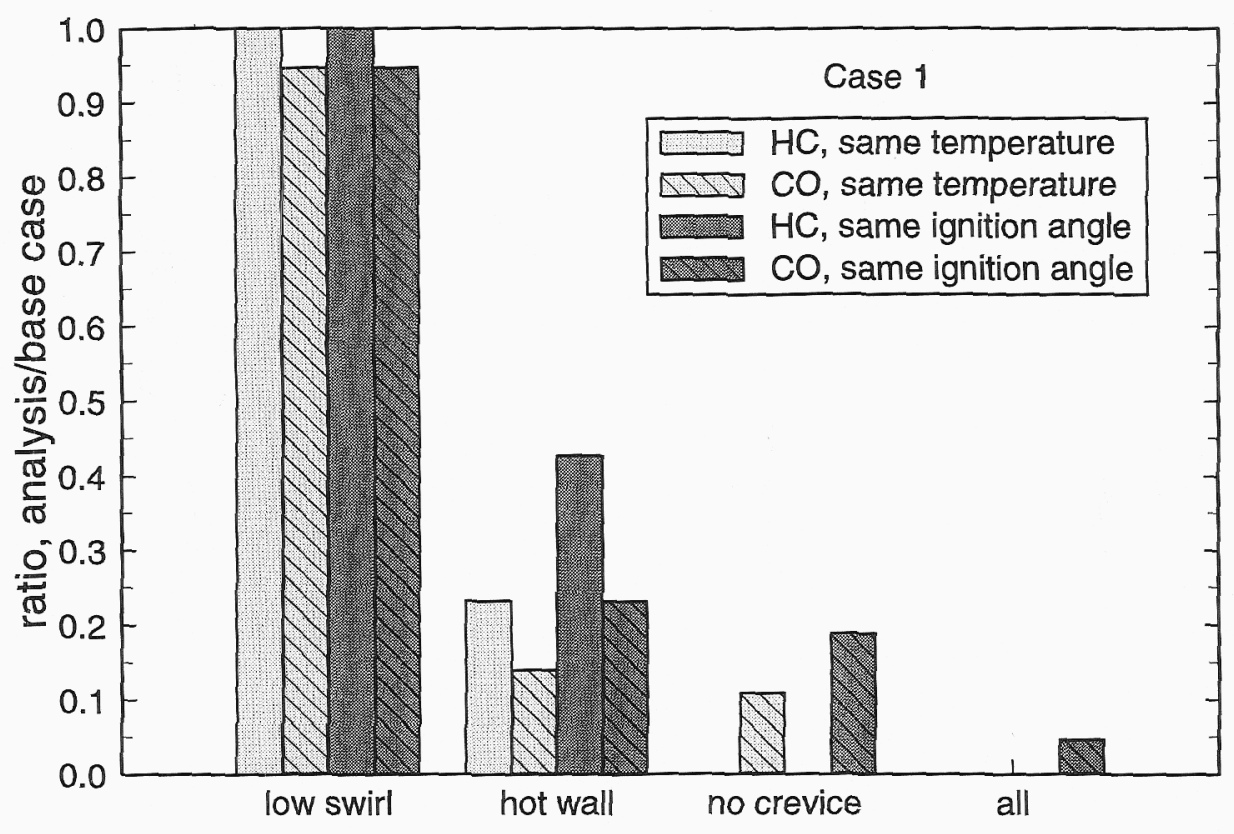

Figure 10. Ratio between the $\mathrm{HC}$ and $\mathrm{CO}$ emissions obtained with the four emissions reduction techniques (low swirl, hot wall, no crevice, and all technologies applied simultaneously) and the emissions calculated for the base case analysis results (Table 2), for Case 1. Notice that the ratios are not calculated with respect to the experimental results. The figure shows results for the condition in which all cases start at the same temperature, and the condition in which the initial temperature is adjusted to obtain equal ignition timing. 
